\title{
Tirant: biografía y novela
}

\section{Tirant: Biography and Novel}

\author{
GIUSEPPE GRILLI \\ Universidad de Roma Tres \\ giuseppe.grilli@uniroma3.it
}

El estudio fija las pautas de la gran novela de Joanot Martorell en el cruce de la prosa del siglo $\mathrm{xV}$, donde la historia asume, con los brotes del humanismo, la dimensión de la biografía. El hombre se coloca, en su espacio de microcosmo, en esa la centralidad que nunca logrará perder en la novela moderna. Empezando por Cervantes y el Quijote el destino de la biografía, sin embargo, irá desarrollando un matiz paradójico, aunque ya inscrito en el antecedente martorelliano: la convivencia entre la seriedad y formalidad de su principio fundacional y su despliegue paródico. Porque la grandeza del hombre está tanto en sus triunfos, como en sus caídas. La novedad de esta perspectiva quedará conformada en el libro inmediatamente posterior del autor (Dal Tirant al Quijote, 1994 y luego 2014).

Palabras Clave: historia, biografía, parodia

Present essay establishes the essentials points of Joanot Martorell's novel in the European context of prose in XV century, when history, with the humanistic explosion, develops a new biography's mode. The man is dispose in the place of microcosm, in this centrality, from then onwards never lost, by modern novel; starting by Cervantes'Quijote, modern biography develops leather a new paradoxical destination, advanced by Marorell: serious and parodic, together living in the same masterpiece. Because the man's greatness consists in his triumphs and same in his defeats. This innovative prospective is confirmed in the next book Dal Tirant al Quijote, 1994 and 2014.

KeYwORDS: history, biography, parodic

$\mathrm{E}$ ntre el siglo XV y el siglo XVII es lugar común reconocer un espacio literario que en gran parte coincide con lo que se va identifícando gradualmente con el Imperio español. Aún antes que la dinastía de los Habsburgo asumiera con Carlos el papel de símbolo y reivindicador de una política y de una cultura, y estoy tentado de decir aquí de una política como cultura, el cardenal Margarit ya había prefigurado los cimientos del edificio. 
La interpretación sigue la línea de la historiografía anglosajona, en particular las conocidas posiciones de Elliott sobre la filosofía política de la Casa de Austria y de R. B. Tate sobre la cultura de los humanistas y secretarios ibéricos del siglo Xv. Respecto a Margarit en el volumen en el cual Tate reivindica más cumplidamente la importancia y la originalidad del pensamiento del cardinal en la renovación del siglo xv, vale la pena releer el fragmento de la dedicatoria a Fernando e Isabel de la obra máxima de Margarit, el Paralipomenon Hispaniae, en el cual se enfatiza el motivo de la caída, y de la necesidad moral de la reconquista de Constantinopla, con acentos que adquieren un valor peculiar para el lector del Tirant lo Blanc:

Quum videamus hujus etatis nostre principes non modo ad dilatandum catholicam fidem non elaborare, verumetiam vim quam continue Turcus christiani nominis hostis in christicolas infert, propulsare recusant ac negligunt alii secum paciscentes, alii tributa illi pendentes, alii omno et desidie vacantes. Ex quo factum est ut etate nostra Turcus ipse, transacto Hellesponto, Bisantium prime illisque Imperium, inde universam Greciam, Dalmatiam, Macedoniam, Epirum aliasque plures provincias, magnam insuper Europe partem a veri Dei religione cultuque averterit et occupaverit (Tate, Joan Margarit, 375-377).

Por otra parte, una España dual recompuesta (Citerior y Ulterior, Castilla y Aragón), que es el centro de la postura de Margarit para Tate, se constata en el texto de Martorell por aquí y por allá con la natural superficialidad ideológica que es propia de la novela. ${ }^{1}$

Una nueva concepción de la península Ibérica y de su papel en Europa preludian, entonces, una extraordinaria temporada literaria destinada a desplazar el baricentro cultural, a imponer nuevas modas y sobre todo a afirmar nuevos valores. En este marco se insertan encuentros y choques de lenguas y culturas. Sin excluir las contribuciones francesas y occitanas, como corolario de una nueva sensibilidad para las lenguas clásicas se afirma un diálogo entre las lenguas ibéricas (catalán, castellano y portugués) y las lenguas itálicas, entendiendo por ellas sobre todo el nuevo latín humanístico o protohumanístico, el toscano de la primera tradición literaria verdaderamente moderna, las hablas y los dialectos que rápidamente tienen un papel fuertemente

${ }^{1}$ Un último dato curioso, pero no cargado de ninguna señal particular, es que la primera alusión al Paralipomenon la da Margarit en su Templum Domini, fechado en 1464 (Tate, Ensayos, 151). La fecha de 1464, como es sabido, retorna periódicamente (Riquer, Aproximació, 283-2S4) a propósito de la dedicatoria del Tirant al Rei expectant.

Medievalia 50, 2018, pp. 65-78 
caracterizador en las formas de lo cómico. Impulsos contrastantes de conservación e innovación se encabalgan, ya sea del punto de vista de las técnicas, que de los contenidos. Lo nuevo asoma entre los residuos del pasado, a menudo ahí donde éste parece más reacio a desaparecer. Por lo tanto es muy arduo, aun si se reconoce todo el conjunto, identificar los rasgos particulares y específicos del cambio, si no es cuando ya estén definidos en una forma clásica. De ahí se deriva que algunas de las obras más significativas se nos presentan como aisladas o sin causa; esto es válido tanto para una experiencia lírica como la de Ausias March, como para la de Garcilaso. Tan cierto es, que a ambos se asigna un papel no solo de innovadores, sino incluso de forjadores de una nueva lengua poética que poco, si no es que nada, tiene que ver con la tradición precedente a ellos. Sin embargo, aún en este caso, cuando se quiera definir y delimitar el sistema con elementos pertinentes e inconfundibles, emerge una maraña de temas, motivos, formas que es imposible reducir a un esquema.

A pesar de lo dicho, en este ambiente de cultura, que naturalmente sufre mutaciones continuas y que está lejos de ser homogéneo, en los dos siglos que lo separan de la afirmación de la edad de la ciencia y de la técnica, se consolida un modelo por encima de cualquier otro. Es la biografía. Biografías verdaderas, noveladas o del todo novelescas; biografías de artistas, de políticos, de soldados; biografías de hombres públicos y biografías mínimas de gente común. Siempre el modelo biográfico, concreto o abstracto, aparece como el único capaz de determinar un reconocimiento, mientras cualquier otro vector se revela mutable. Pero bien visto, la biografía no se configura ni siquiera como género. Difícilmente podría hacerlo cuando, por otra parte, los géneros medievales, tan entremezclados y en ciertos aspectos anárquicos, no están en grado de asegurar un esquema retórico fuerte a través de las artes dictandi y las artes predicandi. Un modo diferente de estudiar y de comunicar vuelve, de hecho, si no inservibles, por lo menos ya no preceptivas aquellas formulaciones. En verdad, todavía estamos muy lejos de las jaulas neoaristotélicas, que se afirman en su rigidez solo al final del periodo. No es entonces una anécdota banal el hecho que un hispanista tan destacado como Carmelo Samoná, ${ }^{2}$ al disponer sus propios escritos para un proyecto orgánico de reedición, haya querido asignar a un volumen titulado L'età di Cario $V$ el lugar central de su propia experiencia de crítico atraído por una literariedad que se extiende de la novela del siglo Xv al teatro barroco con la etapa intermedia de la Celestina.

\footnotetext{
${ }^{2}$ La referencia a Samoná se relaciona con el proyecto de republicación de sus obras en Garzanti (Samoná, "L'età”, 7-200).
} 
Por otra parte, el modelo biográfico, entendido como aproximación a la realidad que se examina, no es ciertamente una novedad: de la vida de Cervantes de Mayáns a las biografías de Croce, ${ }^{3}$ se ha tomado como el canon más adecuado y productivo para comprender y valorar (Riley, "Cervantes”, 69-85).

He mencionado a Cervantes.

Es indudable que entre tantas obras maestras, lo que marca la cultura del Renacimiento y de la Modernidad frente a la cultura medieval, lo que individualiza y resume pluralidad y correlaciones de la cultura en la edad del Imperio español, es una novela, la novela de Cervantes. Una novela que también es una biografía, narración de la vida —o al menos de su parte significativa - de un personaje asumido como históricamente documentable, como documentados son tantos de sus interlocutores narrativos.

Hemos llegado, entonces, al nexo entre biografía y novela. También sería errado suponer que ese nexo se establezca tan tardíamente, a orillas del siglo XVI y en la culminación de toda una nueva experiencia de cultura. Biografía y novela se han encontrado en las culturas ibéricas (pero insisto: es justo hablar de culturas ibéricas y del Mediterráneo) ya en el gran crisol del siglo Xv. Un contacto cuyo contenido no escapa a uno de los primeros exponentes del nuevo género biográfico: Fernán Pérez de Guzmán. Este, en su prólogo a sus Generaciones y semblanzas, traza, siguiendo un ideal ético-político que es ya laico, una clara línea divisoria entre historias "sospechosas e inciertas" y aquellas que al contrario "se fazen bien". Entre las primeras se encuentran aquellas que son "más dignas de maravilla que de fe" (Generaciones, 3-4), como la historia escrita por un tal Pedro del Corral. El ejemplo aquí poco importa, si no es por el dato curioso que uno de los códices que ha transmitido la obra de Corral presenta como prólogo la censura que le había hecho Guzmán. ${ }^{4}$

Biografías y novelas están destinadas a encontrarse desde los primeros intentos. De hecho, durante el siglo, la producción se incrementa progresivamente y se extiende a lo largo de una vasta gama de posibilidades de ejecución. En particular los temas de la fama y del honor, la gesta de los caballeros, el itinerario y el cuento del personaje histórico confluyen en un territorio literario densamente poblado. Las vidas o biografías caballerescas se entrelazan

${ }^{3}$ El Croce biógrafo "hispanista" ha sido repropuesto recientemente por Giuseppe Galasso (Croce, Vite y Storie e leegende).

${ }^{4}$ La 'Crónica Sarracina' de Pedro del Corral es un interesante ejemplo de contaminación entre historiografía y novela en el ámbito castellano (Grilli, "Approssimazioni”, 211-245). El dato curioso del manuscrito de la Biblioteca Escurialense X-i-12 que engloba la crítica en el prólogo de la obra fue hecho notar por Menéndez Pidal (Floresta, 50). 
con cuentos históricos o pseudo-históricos hasta sobreponerse a las narraciones de aventuras inspiradas libremente en la tradición de la novela medieval.

Sostenida, más que por cualquier otro, por Martí de Riquer, la contigüidad de obras como el Jhean de Saintré, El victorial o el Tirant lo Blanc, y las vidas y las aventuras caballerescas del Passo Honroso, del capitán Boucicaut o del caballero Lalaing; o de Sanderberg, Vázquez de Saavedra u otros, no alcanza a definir un género formalizado. ${ }^{5}$ Pero ¿sin la luz refleja de la biografía, podemos captar el sentido de la novela caballeresca? La polarización entre un tipo de discurso, constituido por el género, y una obra determinada, entendida como un fenómeno empírico, parecería revertirse en la transmutación de una miríada de experiencias históricas concretas que se proyectan como fuegos de artificio sobre la sociedad del siglo quince, en la página escrita, documental o literaria. ${ }^{6}$

Habitualmente nos hemos inclinado a distinguir entre documento y fícción sobre la base de parámetros como la verosimilitud, la plausibilidad, la discreción. Riquer, a quien, como se ha visto, tanto se debe por esta aproximación, ha, sin embargo, negado decididamente, y con válidos motivos, tal distinción. En efecto, resultan más increíbles los heroísmos verdaderos que los supuestos: la literatura imita la vida y modera sus ardores. La fragmentariedad es, sin embargo, más aparente que efectiva. Si dirigimos la mirada a la obra entendida singularmente, concretamente al Tirant lo Blanc, que por otra parte es la más auténtica expresión de la literariedad del periodo, notaremos en el prólogo un indicio revelador de la recomposición posible de los fragmentos. Obviamente no en el sentido de una reductio ad unum impensable y del todo ajena al espíritu de la obra, sino en una dirección indicativa de la modalidad, sugerente del conjunto que tan malamente se capta. El prólogo de la novela, y eso se sabe desde hace muchas décadas, no es otra cosa que un plagio - uno entre tantos diseminados a lo largo del texto- del prólogo que Enrique de Villena antepone a su obrita en catalán Los doze treballs d' Hèrcules en 1417. El plagio es de verdad descarado, pero si se lee autónomamente el texto del Tirant, aun con la memoria fija en la obra de Villena, no podemos no reconocer la congruencia del estilo y del argumento.

\footnotetext{
${ }^{5}$ Se recuerdan las etapas esenciales: la primera edición del Tirant lo Blanc de 1947; los capítulos de la Historia de la literatura catalana de 1964; el libro de síntesis (sólo en edición italiana) Cavalleria, tra realtà e letteratura nel Quattrocento de 1970, preparado a partir de ensayos en catalán y castellano de los años sesenta.

${ }^{6}$ En términos generales falta un estudio actualizado de conjunto. Véase todavía Romero, "Sobre la biografía".
}

Medievalia 50, 2018, pp. 65-78 
No diversamente, del resto, de lo que sucederá en el transcurso de la naración cuando episodios enteros y fragmentos serán sabiamente intercalados e integrados en una especie de pastiche literario.

Ahora bien, el autor del Tirant, al seguir a Villena, no comete la imprudencia del copista de Corral: adapta el texto del que copia a las nuevas finalidades que se propone. Los trucos son muchos y no es menester aquí recorrerlos individualmente. Uno puede servirnos de indicador y de guía, Villena escribió:

Molt noble i virtuós cavaller: Jatsia per vulgada fama fos informat de vostres virtuts, molt majorment ara he hagut coneixença d'aquelles per comunicarme i disvetllar vostres lloables desigs, afectant saber los fets dels antics i gloriosos cavallers des quals los poetes i historials han en ses obres comendat, perpe-tuant les llurs recordacions, singularment los treballs del fort Hercules, que per sa virtut fon entre los gentils deificat.

La lectura del Tirant es ligeramente diversa:

Molt excellent, virtuós e gloriós Príncep, Rei expectant: Jatsia per vulgada fama fos informat de vostres virtuts, molt majorment ara he hagut noticia d'aquelles per vostra senyoria volerme comunicar e disvetlar vostres virtuosissims desigs sobre los fets dels antics virtuosos e en fama molt glorio sos cavallers dels quals los poetes e historials han en ses obres comendat perpetuant llurs recordacions e virtuosos actes. E singularment los molt insignes actes de cavalleria d'aquell tan famós cavaller, que, com lo sol resplandeix entre los altres planetes, així resplandeix aquest en singularitat de cavalleria entre els altres cavallers del món, apellat Tirant lo Blanc. ${ }^{7}$

Como se puede ver, la diversidad puede reducirse a una oposición figural. Villena propone el héroe deificat; en el Tirant el personaje, asumiendo sobre sí mismo la responsabilidad de la narración, se asimila al sistema solar donde la primera estrella resplandece sobre los otros planetas.

Entre novelas históricas, biografías, libros de caballería y otros experimentos en prosa, nuestra novela afirma una singularidad retórica aun cuando está mayormente expuesto a caer en la rutina y el género. Por esto, antes de proceder a cualquier consideración sobre la interacción que el Tirant desarrolla en la dinámica literaria, conviene resumir los rasgos que lo caracterizan.

${ }^{7}$ Sobre esta fuente martorelliana y la bibliografía que ha generado véase Riquer, Aproximació, 275-278.

Medievalia 50, 2018, pp. 65-78 
Tres son los elementos estructurantes: el autor, la narración, el estilo. Del autor del Tirant, de aquel que firma el prólogo del libro, no poseemos una biografía. No nos dolemos por la penuria de noticias que tenemos sobre él, sino más bien por la razón opuesta. ${ }^{8}$ De Joanot Martorell de hecho sabemos que fue un caballero valenciano activo en la primera mitad del siglo xv. Sus contactos con la corte de Alfonso, los viajes —entre los cuales una o más estancias en Inglaterra en la corte del rey Enrique-, las disputas públicas y privadas, entre las cuales la furiosa con el seductor de su hermana Damiata, el caballero de Monpalau, las cartas y carteles de desafío con su firma permiten suponer una vida digna de ser el tema de una de las biografías de la época. Más aún que entre los conocidos de Martorell no faltaron personajes cuya biografía pasó a ser materia literaria. Si nos falta el Martorell biografiado, no es menos lícito añorar el Martorell biógrafo: cuñado y amigo del gran March, una biografía suya del poeta habría seguramente resuelto no pocas de las interrogantes que la poesía ausiasmarchiana nos presenta.

Sin embargo, hay huellas del personaje del cual quisiéramos que se contara la vida, y de la de otros, en la colección de cartas que ha llegado hasta nosotros. ${ }^{9}$ De ellas se transparenta una existencia que se delínea en la confrontación con los interlocutores vitales más próximos. No se trata de un epistolario secreto y personal, ni siquiera de un ejercicio literario de estricto sello humanístico y neociceroniano. Las cartas de Martorell tienen el corte de anécdota a la que aluden y dan la sensación de la provisionalidad y al mismo tiempo de la relevancia que el hecho particular ha tenido en la vida del protagonista. Son pues un material en todo consonante con los fines y modos del discurso biográfico.

La novela, gran obra literaria y substancialmente única escrita por el caballero Martorell, tiene diversas intenciones y expresa una manera de la escritura compleja y rica. Aunque los materiales del libro se mantengan unidos por el relato de las proezas del héroe, el joven bretón Tirant, que obtiene la investidura

\footnotetext{
${ }^{8}$ La biografía de Martorell ha sido esencialmente resumida y sistematizada por Riquer en sus estudios tirantianos, utilizando las contribuciones parciales de eruditos, sobre todo el trabajo de A. Ivars, o de estudiosos que han presentado datos nuevos y detalles como Tate. Recientemente han realizado nuevas investigaciones Jaume Chiner y Jesús Villalmanzo que los conducen a plantear una nueva aproximación biográfica que puede llevar a desmentir o a rectificar aspectos no secundarios de la biografía del caballero valenciano. De su estudio, en proceso de publicación, ha aparecido un anticipo en el suplemento de la revista El Temps, 26, 1991, 649-664 (la paginación se refiere a la edición del Tirant como folletó de la revista en el curso del Any del Tirant).

${ }^{9}$ Estas cartas, con el complemento de los carteles de desafío, nos quedan como el dato biográfico más singular y significativo, como han afirmado justamente Martí de Riquer y Mario Vargas Llosa (Combate).
}

Medievalia 50, 2018, pp. 65-78 
directamente del rey de Inglaterra, fundador de la orden de la Jarretera, y que la novela entonces acabe con su muerte, la identificación de la estructura narrativa con la biografía del protagonista no se da por descontada. Este, en efecto, entra en la historia y en la novela ya adulto, adormecido sobre su caballo, y se despierta, por así decirlo, entre los brazos del que había sido por varios capítulos el primer protagonista del libro. Disgresiones - entre ellas auténticos excursus de erudición, intermedios teatrales y otros-, episodios intercalados, relaciones de viajes integran el material de la novela, cuya historia principal (aún desde el punto de vista de la afirmación de la personalidad y de la vitalidad del caballero protagonista) adquiere consistencia solo cuando Tirant arriba a Constantinopla y ahí participa en una trama de aventuras de la cual, a pesar de las repetidas tentativas de la crítica, es imposible eliminar la connotación licenciosa. Pero no basta. La identifícación del entramado de la novela, tal vez precisamente porque se da mediante la asunción del modelo de la comedia humanística y del cuento erótico, pone en evidencia una insurgencia textual ya manifestada precedentemente: la relativa opacidad del héroe protagonista con respecto al núcleo de sus amigos e interlocutores narrativos. Dicho de otra manera: Tirant seguramente es el que ocupa los diversos episodios y asegura la continuidad narrativa, pero desde el punto de vista literario, sin el auxilio de los otros personajes coprotagonistas (Felip de França, Ricomana, Diafebus, Plaerdemavida y así seguido todos los demás) muy pronto nos aburriría con sus estratagemas aprendidas en los libros o con su sentido común. Ni como atleta, ni como estratega sus habilidades son verdaderamente excepcionales.

Lo que hace grande a Tirant, que hace de Tirant una obra maestra, son las situaciones, no por lo que describen (a pesar de que las descripciones sean en la novela ocasiones de extraordinario ilusionismo literario, sin por ello escapar a la regla del realismo), sino por lo que dejan intuir. "Novela moderna”, como ha dicho Dámaso Alonso, el Tirant lo es gracias al estilo. Elementos característicos de la novela son el uso desprejuiciado de las fuentes, numerosísimas las identificadas y probablemente no menos larga la lista de aquellas todavía por señalar; las contaminaciones de registros, esencialmente el coloquial (proverbios, frases hechas, formas rituales) y el curial (modos cancilleriles, calcos latinos, retoricismo); la manipulación lingüística: todos los personajes, sin distinción de papeles fijos, pero sí de situaciones, acuden alternadamente a uno u otro "estilo" de lengua. ${ }^{10}$

${ }^{10}$ La definición de la novela la discuto en "Tirant lo Blanc novela”, 403-423; el motivo de la teatralidad lo trato en la intervención leída en el Simposium Tirant lo Blanc (en prensa), Barcelona 1990. 
Exactamente en esto el modelo de la biografía se asume en profundidad y, al mismo tiempo, es superado. La aceptación no superficial de la biografía como motivación poética del texto, en efecto deriva de la peculiar síntesis estilística. Es una vida verdadera, o vivida, el punto de vista que permite la focalización de los estilos según las situaciones y no según los papeles o caracteres predeterminados. En esto la teatralidad del Tirant, aunque tan fuertemente acentuada, encuentra un límite, que es el límite del género que distingue la novela de la acción en prosa, en la línea que es propia de la Celestina o de La Dorotea. Pero Martorell se aleja de la biografía asignando a las voces de la novela una entidad autónoma respecto a la elocución del narrador, aunque presente y vivaz.

Las polaridades de la biografía y la novela se proyectan por lo tanto sobre dos planos, perfectamente objetivados, en la trama narrativa. Por una parte está la historia, la narración a la que, irónicamente, Martorell asigna el lugar de la fijación vertical. La tradición novelesca se reúne y materializa en los bloques figurativos de los frescos de palacio. Inmóviles, los personajes de la novela han sido atrapados sobre las paredes y sólo accidentalmente —en ocasión de una gran fiesta, por ejemplo - se despegan de los muros para materializarse en la función del actor, como sucede durante algunos capítulos a Arturo y Morgana. ${ }^{11}$

Pero en conjunto les está vedada la vida verdadera, esto es la vida "compleja”, que caracteriza a los personajes de la obra. Aquello que se opone a la "sobtil e artificial pintura" de la tradición narrativa, que comprende a Virgilio, Ovidio y el roman de Chrétien, es la nueva oralidad de los protagonistas martorellianos. Como ha notado Vargas Llosa, la primera impresión de cada lector del Tirant está atraída por el río torrencial de palabras que se descargan sobre la página. ${ }^{12}$ Los personajes ciertamente combaten, aman, viajan de un

${ }^{11}$ Son las historias de "Floris e de Blanxesflors, de Tisbe e de Piramus, d'Eneas e de Dido, de Tristany e d'lsolda, e de la reina Ginebra e de Lançalot” (Tirant lo Blanc, cap. 118, 374). El elenco de los amantes célebres es un tópico presente también en otra gran novela catalana del siglo xv, Curial e Güelfa, pero es peculiar de la obra martorelliana la transformación teatral y por lo tanto la actualización en el texto del repertorio. Cf., en particular sobre el papel de Arturo y Morgana, los ensayos de interpretación de Lola Badía ("De la Faula", 17-57) y Albert Hauf ("Artur a Costantinoble”, 13-31).

${ }^{12}$ Decir que las palabras son importantes en una novela parece una frase cacasena. ¿No lo son siempre acaso? Desde luego. ¿No es por medio de las palabras que se delinean los hechos, los personajes, las situaciones de una ficción? ¿No son ellas, con sus significados, con sus asociaciones y reverberaciones en la memoria, con su música, las que dan cuerpo, movimiento, color, sentido, vida a las historias? Sí, ciertamente. Pero en Tirant lo Blanc las palabras son todavía más que eso: las protagonistas de la historia. Unos personajes tan deslenguados y abundantes, tan intrusos, que a menudo parecen emanciparse de aquello que deberían expresar - los seres humanos, las anécdotas, los decorados, los paisajes, incluso las ideas - y adquirir 
continente a otro, pero sobre todo hablan. El discurso directo prevalece, a menudo prevaricando sobre cualquier otra situación. Así, al inicio el aprendizaje y la formación de Tirant, aunque confiada a un libro escrito y encuadernado, un libro macizo como una piedra, se transforma en una lectura en voz alta, primero solitaria, después ante un público atento de conmilitones. ${ }^{13}$ Así, en el corazón del libro una de las escenas eróticas más precisas en minuciosidad, detalles y focalización de imágenes pasa a través de la narración que hace Plaerdemavida: la muchacha describe lo que ha visto desde su escondite excitada y deseosa de excitarse, como si fuera el resumen matutino de un sueño. ${ }^{14}$ La oralidad se opone a la plasticidad así como la vitalidad del héroe no más solo, se contrapone a la situación ermitaña de quien lo ha precedido en la caballería y en la novela. Y probablemente no carece de significado profundo que la muerte entre en la novela "de rondón", como ha escrito Avalle Arce (Temas hispánicos, 260), justo cuando es evidente el triunfo, social y personal, de los amigos y compañeros más queridos del protagonista.

Sin haberlo afirmado explícitamente, me parece ya haber introducido implícitamente la distinción entre modelo biográfico y novela, o bien entre género y obra.

Una distinción ésta que recalca la que hay entre discurso monológico y dialógico. Esa se atiene de hecho a la diferencia que encontramos entre cuento clausurado y novela polifónica.

La objeción que se podría avanzar sobre la base de la incongruencia del factor estilístico en la determinación del carácter peculiar dialógico del Tirant, apoyada en la substancial unidad del genus en la obra martorelliana, no me parece adecuada. Si de hecho es verdad que todo parece remitir al stilus gravis, ya que el ámbito social es el del miles, el animal dominante el equus, y el instrumento de acción el gladius, el lugar la urbs o los castra, parece incontrovertible que el árbol y el fruto de la novela no son los sublimes laurel y cedro, sino el mediano pomus. Más bien se trata de pometes, son los senos adolescentes de Carmesina de los cuales depende la suerte del Imperio de Oriente y, contextualmente, el oriente del protagonista y de la novela epónima. ${ }^{15}$

una suerte de vida propia, una autosuficiencia ontológica, como ocurre, por ejemplo, con las palabras cantadas de las óperas (que el melómano puede gozar sin necesidad de entender). (Vargas Llosa, Carta de batalla, 94-95).

${ }^{13}$ La referencia es al conocidísimo capítulo 163.

${ }^{14}$ La referencia aquí es al capítulo 39: “...e tota la nit estigueren lleginit les cavalleries que dins lo llibre eren escrites e tot l'ordre de cavalleria” (Tirant lo Blanc, 185).

${ }^{15}$ Recientemente se ha regresado sobre el motivo erótico en el Tirant y en especial sobre lo anómalo del enamoramiento del héroe que ha sido capturado por la doncella por la vía de 
No sin razón Dámaso Alonso al asignar un estatuto a la novela llega a la identificación: "todo un hombre" (Tirant lo Blanc, novela moderna, 502). Es este hombre libre que irrumpe más allá del cerrado perímetro de la norma medieval resumida en el complejo histórico-épico-hagiográfico de las artes dictandi y predicandi. No se cortan naturalmente las ligas con la organización del texto dictada por los cánones de la escritura y del libro: la novela nace de una variante de la historiografía, al parejo de la biografía, como nos ha recordado Pérez de Guzmán. Y no solamente en la tradición occidental, y específicamente catalana (donde aun en la deformación de los datos notamos las confluencias: Martorell dilata sus propios ejércitos no más de cuanto lo había ya hecho un historiador de la honestidad y precisión de Descoit). ${ }^{16}$ También la historiografía bizantina ha reaccionado como canguro en relación con la novela helenística. No tiene ningún valor de documento pero es una curiosidad divertida notar que el texto de las Etiópicas de Heliodoro que está entre los factores desencadenantes de la nueva moda de la novela en toda la Europa occidental de los siglos XV y XVI, fue reencontrado en 1526 en la biblioteca de Matías Corvino. ${ }^{17}$ Y Matías no es otro que el padre de aquel János Húnyadi en cuya biografía seguramente se inspiró Martorell para delinear la figura militar de su Tirant. ${ }^{18}$

La correspondencia es decididamente fortuita, y sin embargo expresa una constelación que bien representa la fortuna de la novela cuya suerte está ligada a la debacle política que la cultura catalana padece entre el siglo xv y el XVI. Por lo tanto no puede maravillar que frente al éxito editorial del siglo XVI de la versión italiana sea mucho más magro el botín de las ediciones en catalán y en español a pesar del entusiasmo de Cervantes (Martines, "El Tirant lo Blanc a Italia”). ${ }^{19}$ Esto explica, en parte, por qué los pruritos clasificatorios del

las pupilas, pero no de las femeninas, sino más bien de las suyas, prisioneras de los senos de la muchacha. Al tema dedico un ensayo que aparecerá en el volumen especial de la Nueva Revista de Filología Hispánica sobre el erotismo en las letras hispánicas. Aquí recuerdo solamente que en la descriptio personae en el Yvain de Chrétien de Troyes el piz es el último de los atributos de la mervoille fine a esgarder. La alteración de los ingredientes realizada por Martorell tiene, tal vez, un eco posterior en Tasso (Gerusalemme, IV, 31).

${ }^{16}$ Para estos cálculos véase Riquer, Aproximació, 218-222.

${ }^{17}$ During the sack of... in 1525 the manuscript of Heliodorus Antthiopica was discovered in "Corvin", the library of King Matthias Corvinus of Hungary. This thirdcentury romance was almost immediately translated from the original Greek into Latin and from Latin into various European languages (Rose, "Alonso Núñez", 89).

${ }^{18}$ Esta identificación, aun con todas las reservas de cualquier proceso indicial, ha sido hoy día ampliamente probada por Constantin Marinescu y K. Faluba (véase bibliografía).

${ }^{19}$ Se recuerden de todos modos las páginas introductivas de Sansone a su edición de la versión de Lelio Manfredi (Tirant lo Blanch, 13-15). 
neoaristotelismo hayan descuidado la obra de Martorell y la hayan asimilado a la tradición de las biografías y los libros de caballería. Esto explica también por qué la crítica decimonónica, atraída por análogos deseos de definiciones preceptivas, haya quedado desconcertada frente al Tirant. Sin embargo, si seguimos las discusiones recientes sobre novel y romance a propósito de la narrativa del Siglo de Oro, o si recorremos con Wardropper las definiciones de la época consignadas en las portadas ("libro", "tratado", "retrato", "vida" en referencia a las temáticas: pastoril, sentimental, picaresca, etc.) nos enfrentamos con una coincidencia singular (Wardropper, “Don Quijote”, 1-11). En ningún género, ni en ninguna obra del género antes del Quijote, si no es en la novela de Joanot Martorell, se da la contaminación entre finalidad y medios expresivos, formas de la expresión y contenido diversos. Los modos de la elocución, en la tripartición canónica, se proyectan en las tres modalidades del amor a las cuales remiten caballería y cortesía. Lo ha reafirmado Estefanía en el capítulo 127 cuando ha deslindado los tres géneros del amor: "com sia cosa acostumada... les donzelles estant en cort se tenen a molta glòria que sien amades e festejades" según las "tres maneres d'amor, ço ès: virtuosa, profitosa, viciosa” (Tirant lo Blanc, 406-407). La conclusión, según la cual la millor es la última, la única que sepa llamar a la memoria toda una larga noche de invierno trascurrida en el lecho perfumado con el gentil hombre escogido, está desmentida por la trama. El amor profitosa triunfa con la pareja formada por la anciana Emperatriz y el joven paje Hipòlit, mientras toda la novela rinde tributo al amor substancialmente virtuoso que ha unido a Tirant y Carmesina.

Historia (y no story), la novela de Martorell no ha por esto perdido la inspiración inicial que le venía de la construcción biográfica. La autenticidad del texto, en su severidad estilística, nunca desmentida, se ha visto mellada solo en cuanto atiende a la irrenunciable vocación novelesca. Esta se expresa mediante una temática diversificada y sin embargo orientada. El motivo heroico y licencioso, la historia narrada, después de diversos acercamientos y tentativas, no tendría el peso y el significado que tiene si no se insertara en el surco del genus gravis de la biografía caballeresca.

Traducción de Aurelio González

\section{BibLIOGRAFÍA}

Alonso, Dámaso, Tirant lo Blanc, novela moderna, Obras completas, t. IV, Madrid: 1975. Avalle ArCe, Juan Bautista, Temas hispánicos medievales, Madrid: 1974. 
BAdiA, Lola, "De la Faula al Tirant, passant, sobretot, pel Llibre de Fortuna e Prudencia”, Quaderns Crema: Deu Anys. Miscel.lània, Barcelona: 1989, 17-57.

Croce, Benedetto, Storie e leggende napoletane, Milano: 1990.

Croce, Benedetto, Vite di avventure di fede e di passione, Milano: 1989.

Faluba, K., “Tirant 'el valac' o Tirant 'Joanet'?”, Miscel.lània Sanchis Guarner, I, 1984, 107-108.

Grilli, Giuseppe, "Approssimazioni alla Cronica Sarracina di Pedro de Corral”, Rendiconti dell'Academia di Archeologia Lettere e Belle Arti di Napoli, XLVI, 1972, 211-245.

GRILLI, GiUseppe, 'Tirant lo Blanc novela de caballería. Interferencia y duplicación en el género", Annali dell Istituto Orientale di Napoli, XXXIII:2, 1991, 403-423.

Hauf, Albert, "Artur a Costantinoble. Entorn a un curiós episodi del Tirant lo Blanc", L'aigualdoç, 12/13, 1990, 13-31.

Marinescu, Constantin, "Du noveau sur Tirant lo Blanch”, Estudis Romanics, IV, 1953-1954, 137-203.

Marinescu, Constantin, "Nuevas notas sobre Tirant lo Blanc", Boletín de la Real Academia de la Historia, CXVIII, 1956, 287-305.

Marinescu, Constantin, "Nouvelles recerches sur Tirant lo Blanch”, Miscel.lània Aramon i Serra, I, 1979, 401-420.

Martines, Vicent, "El Tirant lo Blanc a Italia. In Spagna è riputato come il Decamerone di Giovanni Boccacio”, Actas del IX Col.loqui Internacional de Llengua i Literatura Catalanes, Alacant: 1991 [en prensa].

Martorell, Joanot, Tirant lo Blanc, ed. De Martì de Riquer, Barcelona: 1969.

Martorell, Joanot, Tirant lo Blanch, ed. de G. E. Sansone, versión de Lellio Manfredi, Roma: 1984.

Menéndez Pidal, Ramón, Floresta de leyendas heroicas españolas, I, Madrid: 1958.

Pérez de Guzmán, Fernán, Generaciones y semblanzas, ed. de J. Domínguez Bordona, 6 ${ }^{a}$ ed., Madrid: 1979.

Riley, Edwin C., "Cervantes: A Question of Genre”, en Medieval and Renaissance Studies in Honor of P. E. Russel, Oxford: 1981, 69- 85.

RiQuer, MARTí De, Aproximació al Tirant lo Blanc, Barcelona: 1990.

Riquer, Martín de y Mario Vargas Llosa, El combate imaginario, $2^{\mathrm{a}}$ ed., Barcelona: 1991.

Romero, José Luis, “Sobre la biografía española del siglo xv y los ideales de vida”, Cuadernos de Historia de España, 1-2. 1944, 115-138.

Rose, Constance H., "Alonso Núñez de Reinoso's Contribution to the novel”, en Creation and Re-creation: experiments in Literary Form in Early Modern Spain. Studies in Honor of Stephen Gilman, Newark: 1983.

SAmonÁ, CARMElo, "L'età di Carlo V", en Letteratura spagnola. I secoli d' Oro, Firenze: 1973, 7-200.

Medievalia 50, 2018, pp. 65-78 
TAte, Robert B., Ensayos sobre la historiografía peninsular del siglo XV, Madrid: 1970.

TAte, Robert B., Joan Margarit i Pau cardenal e bisbe de Girona. La seva vida i les seves obres, Barcelona: 1976.

Vargas Llosa, Mario, Carta de batalla por Tirant lo Blanc, Barcelona: 1991.

Wardropper, Bruce W., "Don Quijote: Story or History”, Modern Philology, LXIII, 1965, 1-11. 